\title{
SIGNAL FOR HELP
}

\author{
Ina Vladova, Milena Kuleva \\ National Sports Academy "Vassil Levski" (Bulgaria)
}

\begin{abstract}
The crisis, caused by COVID-19, created a lot of issues in this world. The phenomenon of "domestic abuse" escalated. The pandemic and the lockdowns, unfortunately, aided the "abusers". The victims remained locked with their abusers and their "escape routes" and opportunities for help decreased.

Methods. The aim of the present study is to examine the level of occurrence of violence among student-athletes, as well as their preparedness and competence to react.

Results. From the obtained and presented data, it could be concluded that physical and sexual violence are not widespread among Bulgarian athletes. It is noteworthy that parents are more likely to physically abuse their children than the coaches are. Also, the relationship between the athletes themselves is not under the sign of violence $-82.7 \%(\mathrm{n}=115)$ say that they have never been a victim of physical violence by a teammate, and three of them say they have been a victim of sexual violence by a teammate.

Conclusions. Given the growth in registered cases of violence, incl. the domestic violence, as well as globalization worldwide, it is necessary to implement a unified discrete signal that can be safely shown in the occurrence of violence. This signal is essential so that it can be used when needed from children to adults, from women and men. The promotion of the international signal for help is important in order to prevent and provide timely assistance to victims of violence. It is important for people to know about it, to use it when needed, but also to recognize it when someone uses it.
\end{abstract}

Keywords: violence; domestic abuse; athletes; COVID-19

\section{Introduction}

The crisis, caused by COVID-19, created a lot of issues in this world. The forced staying at home due to the implemented lockdown, put in place to stop the spread of the virus, caused other, unsuspected damage. For many people, their homes turned into a dangerous place. In it, they are restricted, their rights and freedom are also taken away from them, and not directly from the laws created by the separate governments, but by their families. The phenomenon of "domestic abuse" escalated. The pandemic and the lockdowns, unfortunately, aided the "abusers". The victims 
remained locked with their abusers and their "escape routes" and opportunities for help decreased.

Millions of people around the world have become victims of domestic abuse harassed physically, psychologically, emotionally and sexually. For the past year these cases significantly increased in comparison to previous years. In February 2020, alone, the registered cases for domestic abuse reached the same number as for the entire year of 2019 in China (Allen-Ebrahimian 2020). The increase in such cases is not only observed in China, but in other countries as well, whose measures regarding the spread of the COVID-19 virus, have been very strict. Mellisa Godin, 2020 , talks about such trends during the first quarter of 2020. Another example of domestic abuse rising is in the UK, where during the first weeks of the implemented lockdown, there were three times more cases of domestic homicides and murders (Impact of COVID-19 2021).

Another worrying tendency during the pandemic is the rise in abuse in children and teens, women, elderly people and people with any sort of disabilities. These demographic groups are the most vulnerable and are the main victims of all forms of domestic abuse. At this stage, however, there is a lack of reliable data on the actual extent of violence in a pandemic - and in particular with the lockdown introduced in individual countries in the last year and a half, but according to a number of reports, these cases are increasing.

\section{Theoretical Framework}

Globally, according to the WHO, 1 in 6 people over the age of 60 suffers from or is a victim of violence. That's nearly 141 million people. This number can be much higher, as violence against the elderly is one of the most hidden and under-reported violations, both in long-term care institutions and in their homes. Apart from the alarming data on violence against the elderly, the WHO data on violence against women seem to be even more alarming. The organization said in a report that about 736 million women worldwide - 1 in 3 women - are victims of violence - physical and sexual - by their intimate partner, but not only. Approximately 641 million women worldwide are victims of violence by their intimate partner. Given the reported high levels of stigma as well as the insufficient reporting of cases of sexual violence, the true figure is likely to be higher (WHO, 2021). Again, according to the WHO, more than one billion children between the ages of 2 and 17 are victims of some form of violence each year (WHO, 2020).

Given the results of the reports on the level of domestic violence during the COVID-19 crisis, FIFA, WHO and the European Commission have joined forces and have launched a campaign, to support people at risk due to domestic violence, called \#SafeHome. The sports community, and in particular the football community, are teaming up with the World Health Organization and the European Commission to raise awareness, help and protect victims of violence. FIFA President Gianni 
Infantino states that „Violence has no place in homes, just as it has no place in sports. Football has the power to relay important social messages, and through the \#SafeHome campaign, we want to ensure that those people experiencing violence have access to the necessary support services they need" (WHO, 2020).

Unfortunately, athletes are not immune to violence. And when we talk about violence in sports, we mean manifestations of all types of violence: physical, psycho-emotional, sexual, financial, including neglect, which is also treated as such. Research has shown that victims of violence are twice as likely to die, as people of their age who have not faced violence. First of all, violence in all its forms is a huge violation of human rights and of children's rights. Another reason why it is necessary to examine violence is to propose adequate mechanisms for prevention and intervention, to develop standards, procedures, and algorithms for the protection of vulnerable groups, to develop protocols for reporting and responding to such exposure.

In sports, one of the most sensitive and increasingly studied topics is the topic of sexual violence. Research has been conducted with a lot of teams over the past 20 years, but violence in sports started being widely discussed after the big scandal with the US gymnastics team in 2016. The violence in sports is widespread and causes more psychological harm than physical harm. This is the conclusion reached by Stafford, Alexander \& Fry in 2013, in a study conducted among 6,000 studentathletes in the UK, as they note a predominance of psychological violence (75\%) over physical violence (24\%). (Stafford, Alexander \& Fry 2013, Stafford \& Fry 2013).

The violence present in sports is most often seen amongst coaches, teammates, parents and amongst the team members of the club or athletes. The different types of violence can range from purely physical and sexual violence to rudeness and ignorance. Another question is whether people who have been victims of violence consider the fact that they are real victims. Vertommen et al., 2017 in their analysis mention an important fact that considering that up to $95 \%$ of sexual offenses are not being reported (dark number) and that only a small number of reported incidents will lead to an actual conviction, court data only show us 'the tip of the iceberg.'

All forms of violence, as pointed out by the World Health Organization, lead to devastating consequences: the victims are traumatized - physically and mentally, there is a risk of permanent harm, increased anxiety, worry and depression, deteriorating overall health, there is the feeling of loneliness, the people who are victims lose their dignity, trust in others, and hope. Also, acts of violence often lead to the next one. Sometimes - the abuser and the victim are victims at the same time, sometimes they exchange roles.

As mentioned above, during the state of emergency and lockdowns, both in Bulgaria and around the world, when people stayed at home, the number of abuse cases increased. The main victims are children, young people, women, people with disabilities and the elderly. However, due to various reasons, the victims of 
abuse cannot always defend themselves, run away or ask for help - neither from acquaintances not the police or any hotlines. Often times, the abuser is either close to the victim, both in terms of distance but also relationship wise. The whole lockdown and quarantine situation was particularly worrying, given that often the victim and abuser were constantly together - working from home, shopping online, etc, while being limited in terms of social gatherings.

In order to respond to domestic violence and provide timely assistance to the victims, a campaign was launched by the Women's Funding Network together with the Canadian Women's Foundation to create and promote a discrete signal to be used by a victim of violence to indicate, that he or she is in danger-\#SignalForHelp (Figure 1).

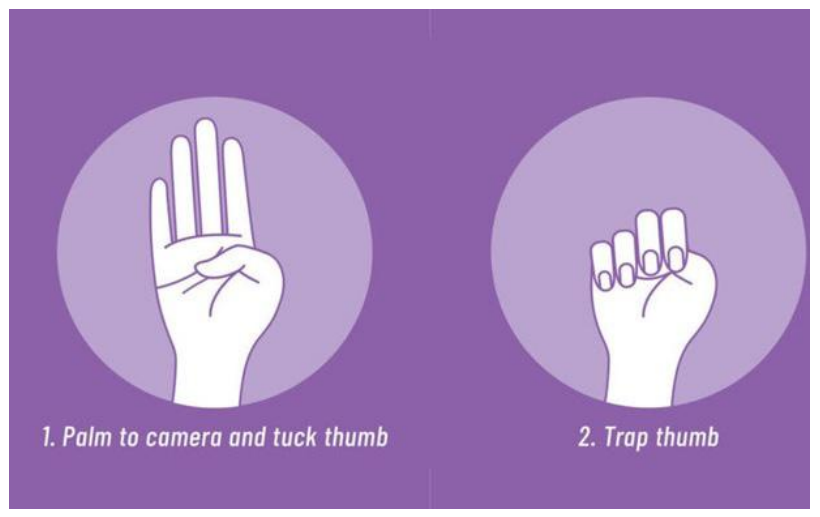

Figure 1. International Hand Signal for help; Pic: Women's Funding Network (Signal for Help 2020)

„Signal for help" or „\#SignalForHelp" is a discreet and international sign for indicating when help is needed and when a person is at risk of violence. It is a gesture performed with one hand by a person who is threatened or is a victim of violence. It can be used during a video call (Figure 2), but also live when meeting an acquaintance or stranger when the abuser is close to the victim. Using it, they signal that they are in danger or feel threatened. This is a discrete alternative to signaling over the phone, for example, when this is not possible for several reasons. When someone signals using this gesture, it is important to be recognized (Figure 3). It should not be ignored, but adequate measures should be taken to provide help or assistance. The signal could be used in a public place, both by the elderly, women, disadvantaged people and children. It is important to be recognized, during video calls, in a public place (Figure 4) and in a gym. In addition to recognition, it is important to provide timely and adequate assistance. 


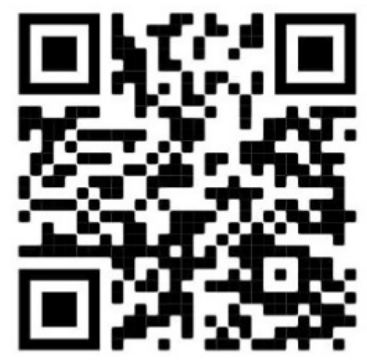

Figure 2. Using the signal during a video call (Violence at Home \#SignalForHelp 2020. Source: YouTube) ${ }^{1)}$

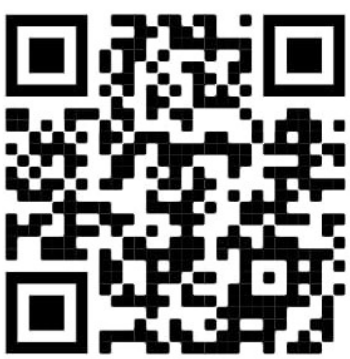

Figure 3. Using and recognizing the help signal (Universal hand signal for help 2021. Source: YouTube) ${ }^{1)}$

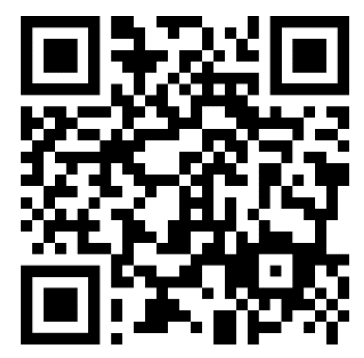

Figure 4. Use of the signal in a public place (Source: FacebookPuntato, L’App degli Operatori di Polizia, 2021)

The number of officially reported abuse cases is so low since very few people, and athletes, know how to properly indicate of such issues. This has also generated interest in the current research to examine whether victims of violence know how to signal that they are a victim of violence, both in or outside of the sports environment.

\section{Methodology}

The aim of the present study is to examine the level of occurrence of violence among student-athletes, as well as their preparedness and competence to react.

To achieve this goal, a task to study and analyze the existing scientific literature was set, to study the world practice of adequate response to violence, especially in cases of domestic violence, as well as available videos on the topic. Through a systematic approach and analysis, we reviewed and selected existing help signals.

To determine the scope of physical and sexual violence among students, an anonymous survey was conducted. For the purposes of the study, an anonymous 
survey in Google Forms was developed, and it was spread for completion online in the first week of April 2021. The questionnaire contained a total of 12 questions. Two of them were demographically oriented - gender and age, and the other questions concerned the violence topic. One of the questions has a dichotomous answer, regarding the self-determination of the respondents whether they feel like a victim of violence. Seven of the questions could be answered on a 4-point Likerttype scale ( 1 - no, it never happened; 2 - yes, it happened once, at most twice; 3 - it happened sometimes; 4 - yes, it happened quite often). This type of question concerned:

- the expression of physical violence by the coaches - for physical violence during the training and after a competition, in case of possible poor performance;

- for acts of sexual violence by the coach;

- for physical violence by parents and expression of physical violence by them in case of possible poor performance during a competition, and the last group of questions;

- for expression of physical and sexual violence by a teammate.

With the last question in the survey, we wanted to examine the level of awareness about the possible reactions in a situation in which the respondents are at risk (in the context of expressions of physical and sexual violence, including domestic violence). The results of the survey were processed with SPSS 21 using Mann Whitney frequency, variation, and comparative analysis.

\section{Results and discussion}

Participants

139 student-athletes from NSA "Vassil Levski" took part in the survey voluntarily. Of these, $52.5 \%(\mathrm{n}=73)$ were women and $47.5 \%(\mathrm{n}=66)$ were men (Table 1). Most of the surveyed participants $(82 \%)$ are club athletes $(n=114)$, and the remaining $18 \%$ of them $(\mathrm{n}=25)$ are national athletes. The surveyed students are divided into three age groups - up to 20 years $(46.8 \%), 21-39(51.8 \%)$ and over 40 years $(1.4 \%)$.

Table 1. Distribution of the surveyed persons by gender

\begin{tabular}{|lr|c|c|}
\hline & & Female (number, \%) & Male (number, \%) \\
\hline & Total & $73(52.5 \%)$ & $66(47.5 \%)$ \\
\hline $\begin{array}{lll}\text { Up to 20-years-old } \\
\text { Between 21-39 years old }\end{array}$ & Age & $41(56.2 \%)$ & $24(36.4 \%)$ \\
Over 40 years old & & $31(42.5 \%)$ & $41(62.1 \%)$ \\
& & $1(1.4 \%)$ & $1(1.5 \%)$ \\
Competitor (at club level) & Club affiliation & $58(79.5 \%)$ & $56(84.8 \%)$ \\
Competitor (national team) & & $15(20.5 \%)$ & $(15.2 \%)$ \\
\hline
\end{tabular}




\section{Violence self-assessment}

As a result of the survey, it was found that $10.1 \%(n=14)$ of the surveyed students self-identified themselves as victims of violence, and their gender distribution was equal.

In addition to the general question of whether students feel and identify themselves as victims of violence in general, they answered in the survey 7 more specific questions that relate to physical and sexual violence by coaches and teammates, as well as physical violence by of parents.

The results of the variation analysis are presented in table. 2 .

Table 2. Results of variation analysis

\begin{tabular}{|l|c|c|c|c|}
\hline Type of violence & Min & Max & M & SD \\
\hline Physical violence - from the coach & 1 & 4 & 1.24 & 0.597 \\
\hline Physical violence - from a coach during or after a competition & 1 & 3 & 1.17 & 0.465 \\
\hline Sexual violence - from the coach & 1 & 3 & 1.01 & 0.170 \\
\hline Physical violence - from a parent & 1 & 4 & 1.42 & 0.780 \\
\hline Physical violence - by a parent during or after a competition & 1 & 4 & 1.07 & 0.374 \\
\hline Physical violence - by a teammate & 1 & 3 & 1.21 & 0.489 \\
\hline Sexual violence - by a teammate & 1 & 4 & 1.04 & 0.280 \\
\hline
\end{tabular}

From the obtained and presented data, it could be concluded that physical and sexual violence are not widespread among Bulgarian athletes. It is noteworthy that parents are more likely to physically abuse their children than the coaches are. Also, the relationship between the athletes themselves is not under the sign of violence $-82.7 \%(\mathrm{n}=115)$ say that they have never been a victim of physical violence by a teammate, and three of them say they have been a victim of sexual violence by a teammate. As sexual violence as a concept is quite broad, this study is limited in its interpretation - and in particular whether it is a more serious sexual act or a type of sexist comment, which is also treated as sexual violence.

As a result of the comparative analysis (Mann-Whitney), no statistically significant differences in gender and age of the participants were found.

\section{Competence to react}

It is noteworthy from the survey that $38.1 \%(n=53)$ of the respondents report that if they find themselves in a situation where they are abused, they do not know how to react safely, to whom to report and whom to ask for help. According to $18 \%$ of the respondents $(\mathrm{n}=25)$ they will try to gain attention to themselves by shouting, hitting, pushing, etc.; $26.6 \%$ of them $(\mathrm{n}=37)$ will try to secretly call on the phone and ask for help. A small part $(\mathrm{n}=10)$ did not answers the question. And only $10.1 \%(\mathrm{n}=14)$ stated that in such a situation they would signal or use a special hand sign (Figure 5). 


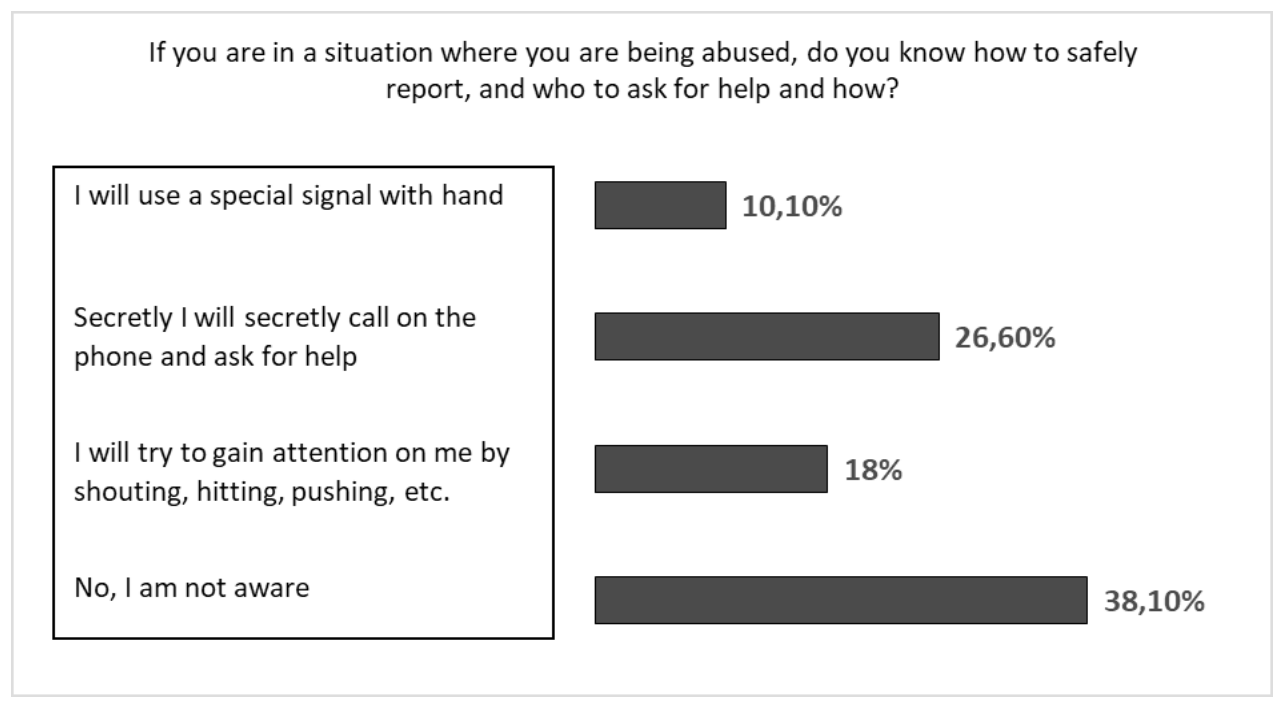

Figure 5. Competence for reaction

From the study it could be conclude that the athletes are not aware of how (safely for themselves) to react to physical and sexual violence. Most of them unconditionally state that they are not familiar.

\section{Conclusion}

Given the growth in registered cases of violence, incl. the domestic violence, as well as globalization worldwide, it is necessary to implement a unified discrete signal that can be safely shown in the occurrence of violence. This signal is essential so that it can be used when needed from children to adults, from women and men.

The promotion of the international signal for help is important in order to prevent and provide timely assistance to victims of violence. It is important for people to know about it, to use it when needed, but also to recognize it when someone uses it.

It is also important for modern sports pedagogical specialist to know about it and to recognize it. To educate and prepare their athletes or students for its use when to use it, what it means, what measures to take, and very importantly when working with children and teenagers - to be educated in good faith and not to speculate on its use.

This signal is important so that there is no need to build installations in different cities around the world, such as the one in the center of Istanbul, called by its author - the graphic designer, musician, and artist Vahit Tuna "The Wall of Shame". He hung 440 pairs of women's shoes, with which he presents the murdered women for 2018 only in Turkey (Stewart 2019). 
Domestic violence is often justified as "punishing" children, sometimes women. The abuser justifies that this is a punishment for bad behavior on their part. But it is important not to make mistake between discipline and harassment and violence, both by parents and by coaches for children and young people.

\section{NOTES}

1. Note: Scan the QR code with Camera app or a special QR reader app.

\section{REFERENCES}

Allen-Ebrahimian, B., 2020. China's coronavirus quarantines raise domestic violence fears. Axios. Available at: https://www.axios.com/ china-domestic-violencecoronavirus-quarantine-7b00c3ba-35bc-4d16afdd-b76ecfb28882.html [Accessed May 18, 2021].

Canadian Woman's Foundation, 2020. Violence at Home \#SignalForHelp, Available at: https://youtu.be/AFLZEQFIm7k [Accessed May 18, 2021].

Godin, M., 2020. How Coronavirus Is Affecting Victims of Domestic Violence. Time. Available at: https://time.com/5803887/coronavirusdomestic-violence-victims/ [Accessed May 16, 2021].

Stafford, A. \& Fry, D. 2013. Playing through pain: Children and young people's experiences of physical aggression and violence in sport. Child Abuse Review, 22, 287 - 299. http://dx.doi.org/10.1002/car

Stafford, A., Alexander, K. \& Fry, D. 2013. There was something that wasn't right because that was the only place, I ever got treated like that: Children and young people's experiences of emotional harm in sport. Childhood, 22(1), 121 - 137. http://dx.doi.org/10.1177/0907568213505625

Universal hand signal for help. (2021). YouTube. https://youtu. be/ 5VQD58UroQ.

Vertommen,T., Kampen, J., Schipper-van Veldhoven, N., Wouters, K., Uzieblo,K., Van Den Eede, F., 2017. Profiling perpetrators of interpersonal violence against children in sport based on a victim survey, Child Abuse \& Neglect 63, $172-182$, https://doi.org/10.1016/j.chiabu.2016.11.029.

WHO, 2020. FIFA, European Commission and World Health Organization launch \#SafeHome campaign to support those at risk from domestic violence, 26 May $2020 \mathrm{https}: / / w w w . w h o . i n t / n e w s / i t e m / 26-05-2020-$ fifaeuropean-commission-and-world-health-organization-launch-safehomecampaign-to-support-those-at-risk-from-domestic-violence

WHO, 2021. Devastatingly pervasive: 1 in 3 women globally experience violence. Younger women among those most at risk: WHO 9 March 2021 https://www.who.int/news/item/09-03-2021-devastatingly-pervasive-1in-3-women-globally-experience-violence 
Women's Aid, 2020. A Perfect Storm: The Impact of the Covid-19 Pandemic on Domestic Abuse Survivors and the Services Supporting Them. Bristol: Women's Aid. https://www.womensaid.org.uk/evidence-hub/ research-and-publications/evidence-briefings-the-impact-of-covid-19on-survivors-and-services/\#1602593534949-f5a4e077-e633 [Accessed May 18, 2021].

Women's Funding Network, 2020. Signal for Help. Women's Funding Network. Available at: https://www.womensfundingnetwork.org/ signalforhelp/ [Accessed May 14, 2021].

Stewart, J, 2019. 440 High Heels Installed on Giant Wall to Honor Female Victims of Domestic Violence. My Modern Met. Available at: https:// mymodernmet.com/vahit-tuna-femicide-art-installation/ [Accessed May 14, 2021].

Facebook. 2021. Puntato, L’App degli Operatori di Polizia. [online] Available at: $<\mathrm{https}: / / \mathrm{fb}$.watch/6qySiZAKUt/> [Accessed 14 May 2021].

$\triangle$ Ina Vladova

https://orcid.org/0000-0001-8235-9647

E-mail: vladova_ina@abv.bg

$\triangle$ Milena Kuleva

https://orcid.org/0000-0002-6467-9644 National Sports Academy "Vassil Levski"

Sofia, Bulgaria

E-mail: milena.kuleva@nsa.bg 